\title{
Long-term predictors of outcome in fatigued employees on sick leave: a 4-year follow-up study
}

\author{
STEPHANIE S. LEONE ${ }^{1 *}$, MARCUS J. H. HUIBERS ${ }^{2,3}$, IJMERT KANT ${ }^{1}$, \\ CONSTANT P. VAN SCHAYCK ${ }^{3}$, GIJS BLEIJENBERG ${ }^{4}$ \\ AND J. ANDRÉ KNOTTNERUS ${ }^{3}$ \\ ${ }^{1}$ Department of Epidemiology, Maastricht University, The Netherlands; ${ }^{2}$ Department of Medical, Clinical, \\ and Experimental Psychology, Maastricht University, The Netherlands $;{ }^{3}$ Department of General Practice, \\ Maastricht University, The Netherlands $;{ }^{4}$ Radboud University Nijmegen Medical Centre, \\ Expert Centre for Chronic Fatigue, The Netherlands
}

\begin{abstract}
Background. Persistent fatigue is strongly associated with functional status and can lead to absenteeism and work disability. Despite several prognostic studies on chronic fatigue, little attention has been paid to occupational outcomes.
\end{abstract}

Method. A total of 127 fatigued employees on sick leave were followed-up after 4 years to determine long-term predictors of work disability, fatigue caseness and chronic fatigue syndrome (CFS)like caseness. Measures included fatigue, physical functioning, illness attributions, psychological problems and emotional exhaustion.

Results. Thirty-three participants $(26 \%)$ were receiving work disability benefits at the 4-year follow-up. Older age and lower levels of physical functioning predicted work disability. Weaker psychological attributions and lower levels of physical functioning were predictors of fatigue caseness. CFS-like caseness was predicted by female gender and lower levels of physical functioning. Self-reported physical functioning remained a strong and statistically significant determinant of work disability [odds ratio (OR) $0 \cdot 45,95 \%$ confidence interval (CI) 0.24-0.87] and CFS-like caseness (OR 0.20,95\% CI 0·09-0.43) after controlling for confounders.

Conclusions. This study suggests that physical functioning plays an important role in the persistence of fatigue complaints and work disability in employees on sick leave. The course of fatigue is a complex process, and exploring temporal relationships between fatigue, functional status and work status in future research could provide valuable information for the improvement of fatigue management.

\section{INTRODUCTION}

Fatigue conditions are poorly understood, difficult to treat and tend to have a poor prognosis (Joyce et al. 1997; Afari \& Buchwald, 2003). To treat fatigue effectively, insight into factors associated with outcome in fatigued patients is necessary. Several prognostic studies have

\footnotetext{
* Address for correspondence: Stephanie Leone, M.A., Department of Epidemiology, Research Institute Caphri, Maastricht University, PO Box 616, 6200 MD Maastricht, The Netherlands. (Email: Stephanie.Leone@epid.unimaas.nl)
}

examined predictors of fatigue and found illness attributions and psychological problems to be important and consistent predictors of outcome in fatigue (Chalder et al. 2003; Schmaling et al. 2003; Skapinakis et al. 2003; Huibers et al. $2004 b$ ). Despite a considerable number of these prognostic studies, few data are available on occupational outcomes in studies of chronic fatigue and chronic fatigue syndrome (CFS) (Ross et al. 2004; Cairns \& Hotopf, 2005). Knowledge of prognostic factors related to occupational outcomes is important because 
persistent fatigue is strongly associated with functional status and can lead to absenteeism and even full work incapacity (Van Amelsvoort et al. 2002; Janssen et al. 2003; Ross et al. 2004). These associations between fatigue, functional status and work status could grow stronger and become intertwined in the course of time, as a result of which the prognosis of fatigue could take a turn for the worse.

In this study, long-term predictors of outcome were examined in a population of persistently fatigued employees already on sick leave. Participants were initially recruited to take part in a randomized controlled trial that aimed to assess the efficacy of cognitive behavioural therapy delivered by general practitioners (GPs) for fatigue and absenteeism (Huibers et al. $2004 a$ ). The intervention did not prove effective at any of the measurements. To gain more insight into factors related to outcome in this group, we aimed to determine predictors of work disability, fatigue caseness and CFS-like caseness, at 4-years' follow-up.

\section{METHOD}

\section{Design}

This was a prospective study conducted within the framework of a randomized controlled trial. More details on the design of the trial are described elsewhere (Huibers et al. 2004a). Participants were initially followed-up at 4,8 and 12 months. These measurements were fixed for each individual participant. A fifth measurement was conducted simultaneously for all participants, as a result of which the mean follow-up period was $3 \cdot 8$ years (range $3 \cdot 1-4 \cdot 8$ years).

\section{Participants}

In the original trial, 151 employees were recruited from an occupational health service. Inclusion criteria were the presence of severe fatigue (a score of 35 or more on the fatigue subscale of the Dutch Checklist for Individual Strength (CIS; Vercoulen et al. 1999; Beurskens et al. 2000) for at least 4 months in combination with complete absenteeism from work for 6-26 weeks. Patients were excluded if they had a medical condition that explained fatigue, were receiving another intervention for fatigue, had a previously classified psychiatric disorder, were receiving current psychological treatment, were receiving a work disability benefit, and if their absenteeism was not health related (e.g. work conflict). In total, 127 participants responded to follow-up and were available for the present analyses. Non-responders at 4 years' follow-up were significantly more fatigued and had significantly lower levels of physical functioning at baseline than responders.

\section{Study variables}

The fatigue subscale of the CIS (Vercoulen et al. 1999; Beurskens et al. 2000) was used to measure fatigue severity. This subscale consists of eight items that are scored on a seven-point scale (score range 8-56). Higher scores indicate higher levels of fatigue severity. Psychological and somatic causal attributions were assessed with a modified version of the Causal Attribution List (CAL), which has been used in previous studies of fatigue (Vercoulen et al. 1996; Prins et al. 2001). The psychological attribution subscale consists of seven items (score range 7-28). The somatic subscale consists of four items (score range 4-16). Higher scores indicate respectively higher levels of psychological attributions and somatic attributions. Physical functioning was assessed with the physical functioning subscale of the Dutch version of the 36-item Short-Form Health Survey (SF-36; Ware \& Sherbourne, 1992; Aaronson et al. 1998). Scores can range from 0 to 100, higher scores indicating higher levels of physical functioning. Psychological distress was measured with the Dutch version of the Symptom CheckList-90 (SCL-90; Derogatis et al. 1973; Arrindel \& Ettema, 1986). Scores can range from 90 to 450 , higher scores indicate higher levels of distress. The Dutch version of the Beck Depression Inventory (BDI) was used to measure depression (Bouman et al. 1985; Beck et al. 1988). Scores can range from 0 to 63, with higher scores indicating higher levels of depression. Emotional exhaustion was measured with the emotional exhaustion subscale of the Dutch validated version of the Maslach Burnout Inventory - General Survey (MBI-GS; Schaufeli et al. 1996; Schaufeli \& Van Dierendonk, 2000). Scores can range from 0 to 6 , higher scores indicating higher levels of emotional exhaustion. Duration of fatigue complaints and duration of absenteeism (i.e. absenteeism due to sick leave) were measured by means of self-reports. 


\section{Outcomes}

\section{Fatigue caseness}

Participants were classified as fatigue cases if they had a score of 35 or higher on the fatigue subscale of the CIS (Vercoulen et al. 1999).

\section{Work disability}

In The Netherlands, employees on sick leave are eligible for a disability benefit (WAO) after being on sick leave for 2 years (previously after 1 year). After this 2-year period, a physician and a labour expert examine the employee and determine whether the employee is awarded either a full or partial disability benefit based on loss of earning capacity (Klingers \& Diepstraten, 1998). Participants indicated by means of selfreport whether they were receiving a full work disability benefit at the time of follow-up. Work disability was only measured at the 4-year follow-up but we also asked patients to report on their work disability status in the 3 years prior to the current study (retrospectively).

\section{CFS-like caseness}

Participants were classified as potential chronic fatigue syndrome cases (CFS-like cases) if they met the following research criteria, which were based on the criteria provided by the Centers for Disease Control and Prevention (CDC) for CFS (Fukuda et al. 1994): a CIS fatigue subscale score of 40 or higher, a self-reported duration of fatigue complaints of 6 months or more, an SF-36 score on physical functioning of 60 or lower, and the self-reported presence of four or more CFS symptoms during the past 6 months. It must be stressed that only a physician can make a true CFS diagnosis. None of the patients received a CFS diagnosis by a physician at the start of the study. The CFS status of patients was measured by self-reports only and therefore the term 'CFS-like' was applied. CFS-like caseness is considered to be a good proxy for a true CFS diagnosis (Taylor et al. 2000; Jason \& Taylor, 2002).

\section{Statistical analysis}

Univariate and multiple logistic regression models were used to determine associations between the predictor variables and work disability $(0=$ no, $1=$ yes $)$, fatigue caseness $(0=$ no,
$1=$ yes $)$ and CFS-like caseness $(0=$ no, $1=$ yes $)$. In the first step of multiple regression analyses, all of the variables that were significantly associated with the outcomes in univariate analyses were entered in the model. Then in the second step demographic variables were entered. A backward stepwise procedure was used. In addition, multiple regression analyses were carried out with the change scores between baseline (t0) and the 12-month follow-up ( $\mathrm{t} 3$ ) of the remaining significant predictors entered in the model. The change scores were calculated by subtracting the scores at the 12-month followup from the baseline scores. A backward stepwise procedure was also used in these analyses. Because of the results of the predictive analyses, additional explanatory analyses were performed to further explore the relationship between physical functioning and the outcome measures. Multiple logistic regression models were also used for these analyses. In a first step, physical functioning was entered in the model. Demographic variables were entered as potential confounders in a second step. In a third step, fatigue severity and duration of fatigue complaints were controlled for. In a final step, psychological attributions, somatic attributions, psychological problems and duration of absenteeism, allocated treatment group and follow-up period were entered as potential confounders. CFS status at baseline, allocated treatment in the original trial and follow-up period were controlled for in all the predictive analyses, but did not alter any of the findings and were therefore omitted from the analyses. All odds ratios (ORs) of continuous variables are expressed in change per standard deviation (s.D.) on the scale. All analyses were performed using SPSS version 12 (SPSS Inc., Chicago, IL, USA).

\section{RESULTS}

Table 1 summarizes the patients' characteristics at baseline and at the 4-year follow-up.

\section{Work disability, fatigue and CFS-like cases}

Table 2 presents the course of outcome in our sample. Thirty-three participants $(26 \%)$ were claiming work disability benefits at the 4-year follow-up. The level of work disability was found to be similar over the 4 years, at 
Table 1. Characteristics of participants at baseline and follow-up

\begin{tabular}{llc}
\hline \hline & \multicolumn{1}{c}{$\begin{array}{c}\text { Baseline } \\
(n=127)\end{array}$} & $\begin{array}{c}\text { Four-year } \\
\text { follow-up } \\
(n=127)\end{array}$ \\
Variables (instrument, scale) & $44 \cdot 1(8 \cdot 2)$ & $47 \cdot 7(8 \cdot 4)$ \\
\hline Age (years) & $56(44)$ & $56(44)$ \\
$\begin{array}{l}\text { Gender, number male (\% male) } \\
\text { Education, number (\%) }\end{array}$ & $35(28)$ & $35(28)$ \\
$\quad$ High & $64(50)$ & $64(50)$ \\
$\quad$ Middle & $28(22)$ & $28(22)$ \\
$\quad$ Low & $48 \cdot 1(6 \cdot 2)$ & $34 \cdot 2(14 \cdot 2)$ \\
Fatigue severity (CIS, 8-56) & $27 \cdot 7(29 \cdot 0)$ & N.A. \\
$\begin{array}{l}\text { Duration of fatigue } \\
\text { complaints (months) }\end{array}$ & $12 \cdot 2(4 \cdot 7)$ & N.A. \\
$\begin{array}{l}\text { Duration of absenteeism (weeks) } \\
\text { Physical functioning (SF-36, 0-100) }\end{array}$ & $63 \cdot 9(23 \cdot 6)$ & $70 \cdot 3(24 \cdot 8)$ \\
Psychological problems & $179 \cdot 7(49 \cdot 4)$ & $148 \cdot 2(44 \cdot 4)$ \\
$\quad$ (SCL-90, 90-450) & $3 \cdot 4(1 \cdot 5)$ & $2 \cdot 6(1 \cdot 5)$ \\
$\begin{array}{l}\text { Emotional exhaustion } \\
\text { (MBI-GS, 0-6) }\end{array}$ & $14 \cdot 4(7 \cdot 6)$ & $9 \cdot 8(7 \cdot 5)$ \\
$\begin{array}{l}\text { Depression (BDI, 0-63) } \\
\text { Psychological attribution } \\
\quad \text { (CAL, 7-28) }\end{array}$ & $19 \cdot 0(4 \cdot 4)$ & N.A. \\
Somatic attribution (CAL, 4-16) & $9 \cdot 1(2 \cdot 6)$ & N.A. \\
\hline \hline
\end{tabular}

Data are mean values (S.D.) or $n(\%)$.

CIS, Checklist for Individual Strength; SF-36; 36-item ShortForm Health Survey; SCL-90, Symptom CheckList-90; MBI-GS, Maslach Burnout Inventory-General Survey; BDI, Beck Depression Inventory; CAL, Causal Attribution List; N.A., not available; s.D., standard deviation.

approximately $30 \%$. At baseline, $41 \%$ of the participants met criteria for CFS-like caseness. Although there was an overall decrease in fatigue and CFS-like cases in the course of the 4 years, there was a slight increase in fatigue and CFS-like cases between the 12-month and 4-year follow-ups, which could indicate a relapse of complaints.

\section{Univariate associations}

Table 3 presents the univariate associations of the potential predictors with outcome at the 4-year follow-up. Older age, a lower level of physical functioning and a higher level of emotional exhaustion were significantly related to work disability at follow-up. Factors associated with fatigue were a longer duration of fatigue complaints, lower levels of physical functioning, a lower level of psychological attribution and a higher level of somatic attribution. Female gender, a higher level of fatigue, a lower level of physical functioning and a lower level of psychological attribution were associated with CFS-like caseness at follow-up.
Table 2. Number (\%) of work disability, fatigue cases and CFS-like cases in the course of 4 years

\begin{tabular}{lccc}
\hline \hline & $\begin{array}{c}\text { Tweline-month } \\
(n=127)\end{array}$ & $\begin{array}{c}\text { Four-year } \\
\text { follow-up } \\
(n=127)\end{array}$ & $\begin{array}{c}\text { Follow-up } \\
\text { follow } \\
(n=127)\end{array}$ \\
\hline Work disability & $0(0)$ & N.A. & $33(26)$ \\
Fatigue cases & $127(100)$ & $63(53)$ & $72(57)$ \\
CFS-like cases & $52(41)$ & $24(20)$ & $33(27)$ \\
\hline \hline
\end{tabular}

CFS, chronic fatigue syndrome; N.A., not available.

\section{Multivariate analyses}

Table 4 shows the multivariate prediction models for outcome at the 4-year follow-up. Older age, female gender and a lower level of physical functioning were strong predictors of work disability at follow-up. Predictors of fatigue were lower levels of physical functioning and lower levels of psychological attribution. Female gender and lower levels of physical functioning were predictors of CFS-like caseness at follow-up.

A change towards a lower level of physical functioning between baseline and the 12-month follow-up was a significant predictor of work disability, fatigue and CFS-like caseness at the 4-year follow-up (Table 4). A change score of psychological attribution could not be added to the regression model for fatigue, as this variable was not measured at the 12-month follow-up.

\section{Physical functioning as a predictor of outcome}

Physical functioning appeared to be a strong predictor in all our models. We therefore analysed the relative contribution of physical functioning as a prognostic factor to outcome. Table 5 shows that lower levels of physical functioning remained associated with work disability and CFS-like caseness when controlling for potential confounders. The association between physical functioning and fatigue lost its significance after controlling for confounders in the final step of the analysis.

\section{DISCUSSION}

\section{Summary of main findings}

We aimed to gain more insight into factors predicting outcome in a group of fatigued employees on sick leave following treatment 
Table 3. Crude associations between baseline predictors and outcome measures at the 4-year follow-up

\begin{tabular}{|c|c|c|c|c|c|c|}
\hline & \multicolumn{2}{|c|}{ Work disability } & \multicolumn{2}{|c|}{ Fatigue } & \multicolumn{2}{|c|}{ CFS-like caseness } \\
\hline & OR & $95 \% \mathrm{CI}$ & OR & $95 \% \mathrm{CI}$ & OR & $95 \% \mathrm{CI}$ \\
\hline Age & 1.98 & $1 \cdot 24-3 \cdot 13$ & $0 \cdot 89$ & $0 \cdot 63-1 \cdot 27$ & $1 \cdot 13$ & $0 \cdot 75-10 \cdot 69$ \\
\hline Gender (male = reference group) & $1 \cdot 84$ & $0 \cdot 80-4 \cdot 21$ & 1.63 & $0 \cdot 80-3 \cdot 31$ & $2 \cdot 4$ & $1 \cdot 02-5 \cdot 83$ \\
\hline \multicolumn{7}{|l|}{ Education } \\
\hline High (reference group) & $1 \cdot 00$ & & $1 \cdot 00$ & & $1 \cdot 00$ & \\
\hline Middle & $1 \cdot 00$ & $0 \cdot 33-3 \cdot 00$ & $4 \cdot 5$ & $1 \cdot 55-13 \cdot 06$ & $1 \cdot 19$ & $0 \cdot 38-3 \cdot 70$ \\
\hline Low & $0 \cdot 765$ & $0 \cdot 28-2 \cdot 09$ & $2 \cdot 5$ & $0 \cdot 98-6 \cdot 18$ & 0.99 & $0 \cdot 35-2 \cdot 79$ \\
\hline Fatigue severity & $1 \cdot 06$ & $0 \cdot 71-1 \cdot 59$ & $1 \cdot 35$ & $0.94-1.92$ & 1.69 & $1 \cdot 07-2 \cdot 66$ \\
\hline Duration of fatigue complaints & $1 \cdot 26$ & $0.86-1 \cdot 83$ & $1 \cdot 58$ & $1 \cdot 03-2 \cdot 36$ & $1 \cdot 30$ & $0.89-1.88$ \\
\hline Duration of absenteeism & $0 \cdot 91$ & $0 \cdot 59-1 \cdot 42$ & 0.97 & $0.68-1.38$ & $0 \cdot 82$ & $0 \cdot 50-1 \cdot 34$ \\
\hline Physical functioning & $0 \cdot 52$ & $0 \cdot 34-0 \cdot 81$ & $0 \cdot 46$ & $0 \cdot 31-0 \cdot 70$ & $0 \cdot 29$ & $0 \cdot 17-0 \cdot 51$ \\
\hline Psychological problems & $1 \cdot 00$ & $0.67-1 \cdot 56$ & $1 \cdot 10$ & $0.78-1.63$ & $1 \cdot 16$ & $0 \cdot 78-1 \cdot 72$ \\
\hline Emotional exhaustion & 1.56 & $1 \cdot 03-2 \cdot 36$ & $0 \cdot 73$ & $0 \cdot 51-1 \cdot 05$ & $1 \cdot 21$ & $0 \cdot 81-1 \cdot 81$ \\
\hline Depression & $0 \cdot 90$ & $0.60-1 \cdot 35$ & $1 \cdot 06$ & $0 \cdot 75-1 \cdot 52$ & $1 \cdot 16$ & $0.78-1.71$ \\
\hline Psychological attribution & 0.73 & $0 \cdot 49-1 \cdot 08$ & $0 \cdot 51$ & $0 \cdot 34-0 \cdot 76$ & $0 \cdot 61$ & $0 \cdot 40-0 \cdot 92$ \\
\hline Somatic attribution & $1 \cdot 23$ & $0 \cdot 82-1 \cdot 85$ & 1.66 & $1 \cdot 14-2 \cdot 42$ & $1 \cdot 41$ & $0 \cdot 92-2 \cdot 15$ \\
\hline
\end{tabular}

Odds ratios (ORs) of continuous variables are expressed as change per standard deviation (s.D.): higher scores on the scales of continuous variables indicate a higher age, higher levels of fatigue severity, a longer duration of complaints, a longer duration of absenteeism, higher levels of physical functioning, higher levels of psychological problems, higher levels of emotional exhaustion, higher levels of depression, and higher levels of psychological and somatic attributions compared to lower scores.

Bold values indicate statistically significant associations.

CFS, chronic fatigue syndrome; CI, confidence interval.

Table 4. Results of multiple regression analysis: associations between baseline predictors, change predictors and outcome measures at the 4-year follow-up

\begin{tabular}{|c|c|c|c|c|c|c|}
\hline & \multicolumn{2}{|c|}{ Work disability } & \multicolumn{2}{|c|}{ Fatigue } & \multicolumn{2}{|c|}{ CFS-like caseness } \\
\hline & OR & $95 \% \mathrm{CI}$ & OR & $95 \% \mathrm{CI}$ & OR & $95 \% \mathrm{CI}$ \\
\hline \multicolumn{7}{|l|}{ Model including only baseline predictors } \\
\hline Age & $2 \cdot 72$ & $1 \cdot 56-4 \cdot 75$ & & & & \\
\hline Gender $($ male $=$ reference group $)$ & $3 \cdot 50$ & $1 \cdot 29-9 \cdot 55$ & & & $3 \cdot 15$ & $1 \cdot 15-8 \cdot 63$ \\
\hline Physical functioning & $0 \cdot 46$ & $0 \cdot 29-0.73$ & $0 \cdot 51$ & $0 \cdot 33-0 \cdot 77$ & $0 \cdot 27$ & $0 \cdot 15-0 \cdot 49$ \\
\hline Psychological attribution & & & $0 \cdot 56$ & $0 \cdot 37-0 \cdot 86$ & & \\
\hline \multicolumn{7}{|c|}{ Model including baseline and change predictors } \\
\hline Age & 1.96 & $1 \cdot 17-3 \cdot 29$ & & & & \\
\hline Gender $($ male $=$ reference group) & & & & & $3 \cdot 00$ & $1 \cdot 00-8 \cdot 99$ \\
\hline Physical functioning & $0 \cdot 26$ & $0 \cdot 14-0 \cdot 47$ & $0 \cdot 20$ & $0 \cdot 10-0 \cdot 41$ & $0 \cdot 15$ & $0 \cdot 07-0 \cdot 34$ \\
\hline Psychological attribution & & & $0 \cdot 58$ & $0 \cdot 36-0.94$ & & \\
\hline Physical functioning change score $\mathrm{t} 0-\mathrm{t} 3$ & 3.63 & $1 \cdot 93-6 \cdot 97$ & 3.63 & $1 \cdot 93-6 \cdot 84$ & $2 \cdot 38$ & $1 \cdot 38-4 \cdot 14$ \\
\hline
\end{tabular}

Odds ratios (ORs) of continuous variables are expressed as change per standard deviation (s.D.): higher scores on the scales of continuous variables indicate a higher age, higher levels of physical functioning, higher levels of psychological attributions, and a change towards a lower level of physical functioning between $\mathrm{t} 0$ and $\mathrm{t} 3$ compared to lower scores.

$\mathrm{CFS}$, chronic fatigue syndrome; CI, confidence interval.

for fatigue in the long term. The prognosis of fatigue in this sample was rather poor, with $57 \%$ of the participants meeting criteria for severe fatigue and $27 \%$ meeting the criteria for CFS-like caseness. Work disability was also high as $26 \%$ of participants reported receiving full work disability benefits at follow-up.

We found work disability to be predicted by older age, lower levels of physical functioning and a decline in physical functioning between baseline and the 12-month follow-up. Fatigue caseness was found to be predicted by lower levels of physical functioning, lower levels of psychological attribution and a decline in physical functioning. Being a woman, having lower levels of physical functioning and a decline in physical functioning predicted CFSlike caseness. 
Table 5. Physical functioning at baseline as a risk factor for work disability, fatigue and CFSlike caseness at the 4-year follow-up

\begin{tabular}{|c|c|c|c|c|c|}
\hline \multicolumn{2}{|c|}{ Work disability } & \multicolumn{2}{|c|}{ Fatigue } & \multicolumn{2}{|c|}{ CFS-like caseness } \\
\hline OR & $95 \% \mathrm{CI}$ & OR & $95 \% \mathrm{CI}$ & OR & $95 \% \mathrm{CI}$ \\
\hline $0.52^{\mathrm{a}}$ & $0 \cdot 34-0 \cdot 81$ & $0 \cdot 46^{\mathrm{a}}$ & $0 \cdot 31-0 \cdot 70$ & $0 \cdot 29^{\mathrm{a}}$ & $0 \cdot 17-0 \cdot 51$ \\
\hline $0 \cdot 45^{\mathrm{b}}$ & $0 \cdot 28-0 \cdot 75$ & $0.54^{\mathrm{b}}$ & $0 \cdot 35-0 \cdot 83$ & $0 \cdot 25^{\mathrm{b}}$ & $0 \cdot 14-0 \cdot 46$ \\
\hline $0 \cdot 43^{\mathrm{c}}$ & $0 \cdot 26-0 \cdot 73$ & $0.54^{\mathrm{c}}$ & $0 \cdot 35-0.85$ & $0 \cdot 26^{\mathrm{c}}$ & $0 \cdot 14-0 \cdot 50$ \\
\hline $0 \cdot 45^{\mathrm{d}}$ & $0 \cdot 24-0.87$ & $0 \cdot 70^{\mathrm{d}}$ & $0 \cdot 40-1 \cdot 24$ & $0 \cdot 20^{\mathrm{d}}$ & $0 \cdot 09-0 \cdot 43$ \\
\hline
\end{tabular}

CFS, chronic fatigue syndrome; CI, confidence interval.

Odds ratios (ORs) of continuous variables are expressed as change per standard deviation (s.D.): higher scores on the physical functioning scale indicate higher levels of physical functioning.

a Crude association.

b Corrected for age, gender and education.

c Corrected for age, gender, education, fatigue severity and duration of fatigue complaints.

d Corrected for age, gender, education, fatigue severity, duration of fatigue complaints, psychological attributions, somatic attributions, psychological problems, duration of absenteeism, group allocation and follow-up period.

We also focused on the role of physical functioning as a specific prognostic factor. After controlling for various confounders, we found that the association between physical functioning and work disability and CFS-like caseness remained significant, while the association between physical functioning and fatigue caseness did not. The magnitude of the associations found stands out in all of the analyses. In particular, the magnitude of the associations between physical functioning and the outcomes of this study are noteworthy.

\section{Methodological considerations}

In two recent reviews it was concluded that occupational outcomes are rarely assessed in prognostic studies of chronic fatigue and CFS (Ross et al. 2004; Cairns \& Hotopf, 2005). Besides examining predictors of fatigue and CFS-like caseness, we also focused on predictors of work disability. Furthermore, this was the first study to present long-term predictors of outcome in a group of fatigued employees on sick leave. A potential limitation is that CFS-like caseness was assessed as a composite variable made up of self-reported fatigue severity, duration of fatigue complaints, physical functioning and four or more CFS symptoms. CFS-like caseness is considered to be a good indicator of true CFS but only a physician can give a diagnosis of CFS (Fukuda et al. 1994; Taylor et al. 2000; Jason \& Taylor, 2002). None of the patients had received a diagnosis of CFS by a physician at the start of this study. However, this may have improved the internal validity of this study as CFS-like caseness was not dependent on help-seeking behaviour and the variation between physicians in diagnosing CFS. Another aspect of the internal validity concerns selection bias during the inclusion of participants in this study and during follow-up. It is not very likely that selection bias occurred during the inclusion of participants, as participants were not selected based on prognostic variables in the study. Nonresponders at follow-up differed significantly from the responders on baseline fatigue scores and physical functioning scores. As this difference was to the disadvantage of the nonresponders, the results presented in this study could be an underestimation of the severity of health problems in the target population. The participants in this study originally took part in a randomized controlled trial with specific inclusion criteria, including being on sick leave for at least 6 weeks. It is questionable, therefore, whether the findings of this study can be generalized to a wider range of fatigued patients who are not on sick leave. Moreover, fatigued individuals with a shorter duration of sick leave may have a different prognosis than the participants in this study.

\section{The role of illness attributions}

Previous studies have shown that illness attributions can play an important role in the course of fatigue conditions not meeting the criteria for CFS (Sharpe et al. 1992; Clark et al. 1995; Chalder et al. 2003; Huibers et al. 2004 b). In this study, absence of a tendency towards psychological attributions was associated with fatigue caseness.

However, causal attributions were not related to CFS-like caseness in this sample, in contrast to several previous studies examining the role of illness attributions in diagnosed CFS patients (Wilson et al. 1994; Cope et al. 1996; Vercoulen et al. 1996; Van der Werf et al. 2002).

\section{Physical functioning as a predictor}

Physical functioning was found to be a robust predictor of outcome in this study. Like physical 
functioning at baseline, deterioration of physical functioning between the baseline measurement and 12-month follow-up predicted work disability, fatigue caseness and CFS-like caseness at the 4-year follow-up. Fatigue has been shown to be related to work disability (Van Amelsvoort et al. 2002; Janssen et al. 2003), but in this study it seems it is not so much the fatigue but the diminished physical functioning associated with fatigue that is the most important factor in the course of fatigue in employees on sick leave. The finding that physical functioning is a predictor of CFS-like caseness after 4 years is consistent with the finding that physical functioning was a significant predictor of CFS-like caseness in a prospective study in this group at the 12-month follow-up (Huibers et al. 2004 b). A recent study also found functional impairment in combination with CFS status to be predictive of final fatigue following treatment for chronic fatigue in primary care (Darbishire et al. 2005). Furthermore, it was found that functional impairment was a significant predictor of fatigue severity in CFS patients (Vercoulen et al. 1996). The results of this study underline the important role of physical functioning in the persistence of fatigue complaints and work disability. It also highlights the need to target the level of physical functioning in the treatment of fatigued patients.

\section{CONCLUSIONS}

The course of fatigue is a complex process with many factors contributing to its persistence or recovery. However, fatigue itself is not necessarily the main factor to focus on in the prognosis of fatigue conditions, as this study underlines. Factors such as physical functioning, work status and illness perceptions seem to become intertwined with fatigue at some time. This makes it difficult to treat fatigue conditions effectively because it is not known how and when these factors influence each other. To further our understanding of fatigue conditions these complex inter-relationships should be examined in future research. In this sense, exploring the temporal relationships between these factors could yield valuable information that can help us improve the care of fatigued patients.

\section{ACKNOWLEDGEMENTS}

This study was funded by the Health Research and Development Council (ZonMw), The Netherlands (grant no. 21000104).

\section{DECLARATION OF INTEREST}

None.

\section{REFERENCES}

Aaronson, N. K., Muller, M., Cohen, P. D., Essink-Bot, M. L., Fekkes, M., Sanderman, R., Sprangers, M. A., te Velde, A. \& Verrips, E. (1998). Translation, validation, and norming of the Dutch language version of the SF-36 Health Survey in community and chronic disease populations. Journal of Clinical Epidemiology 51, 1055-1068.

Afari, N. \& Buchwald, D. (2003). Chronic fatigue syndrome: a review. American Journal of Psychiatry 160, 221-236.

Arrindel, W. A. \& Ettema, J. H. M. (1986). Symptom Checklist-90, SCL-90: Manual for a Multi-dimensional Indicator of Psychopathology [in Dutch]. Swets \& Zeitlinger: Lisse.

Beck, A. T., Steer, R. A. \& Garbin, M. G. (1988). Psychometric properties of the Beck Depression Inventory - 25 years of evaluation. Clinical Psychology Review 8, 77-100.

Beurskens, A. J., Bultmann, U., Kant, I., Vercoulen, J. H., Bleijenberg, G. \& Swaen, G. M. (2000). Fatigue among working people: validity of a questionnaire measure. Occupational and Environmental Medicine 57, 353-357.

Bouman, T. K., Luteijn, F. A., Albersnagel, F. A. \& van der Ploeg, F. A. E. (1985). Some experiences with the Beck Depression Inventory (BDI) [in Dutch]. Gedrag: Tijdschrift voor Psychologie 13, 13-24.

Cairns, R. \& Hotopf, M. (2005). A systematic review describing the prognosis of chronic fatigue syndrome. Occupational Medicine 55, 20-31.

Chalder, T., Godfrey, E., Ridsdale, L., King, M. \& Wessely, S. (2003). Predictors of outcome in a fatigued population in primary care following a randomized controlled trial. Psychological Medicine 33, 283-287.

Clark, M. R., Katon, W., Russo, J., Kith, P., Sintay, M. \& Buchwald, D. (1995). Chronic fatigue: risk factors for symptom persistence in a 2 1/2-year follow-up study. American Journal of Medicine 98, 187-195.

Cope, H., Mann, A., Pelosi, A. \& David, A. (1996). Psychosocial risk factors for chronic fatigue and chronic fatigue syndrome following presumed viral illness: a case-control study. Psychological Medicine 26, 1197-1209.

Darbishire, L., Seed, P. \& Ridsdale, L. (2005). Predictors of outcome following treatment for chronic fatigue. British Journal of Psychiatry 186, 350-351.

Derogatis, L. R., Lipman, R. S. \& Covi, L. (1973). SCL-90: an outpatient psychiatric rating scale-preliminary report. Psychopharmacological Bulletin 9, 13-28.

Fukuda, K., Straus, S. E., Hickie, I., Sharpe, M. C., Dobbins, J. G. \& Komaroff, A. (1994). The chronic fatigue syndrome: a comprehensive approach to its definition and study. International Chronic Fatigue Syndrome Study Group. Annals of Internal Medicine 121, 953-959.

Huibers, M. J., Beurskens, A. J., Van Schayck, C. P., Bazelmans, E., Metsemakers, J. F., Knottnerus, J. A. \& Bleijenberg, G. (2004a). Efficacy of cognitive-behavioural therapy by general practitioners for unexplained fatigue among employees: randomised controlled trial. British Journal of Psychiatry 184, 240-246.

Huibers, M. J., Bleijenberg, G., van Amelsvoort, L. G., Beurskens, A. J., van Schayck, C. P., Bazelmans, E. \& Knottnerus, J. A. 
$(2004 b)$. Predictors of outcome in fatigued employees on sick leave: results from a randomised trial. Journal of Psychosomatic Research 57, 443-449.

Janssen, N., Kant, I. J., Swaen, G. M. H., Janssen, P. P. M. \& Schroer, C. A. P. (2003). Fatigue as a predictor of sickness absence: results from the Maastricht cohort study on fatigue at work. Occupational and Environmental Medicine 60, 71-76.

Jason, L. A. \& Taylor, R. R. (2002). Applying cluster analysis to define a typology of chronic fatigue syndrome in a medicallyevaluated, random community sample. Psychology and Health 17, 323-337.

Joyce, J., Hotopf, M. \& Wessely, S. (1997). The prognosis of chronic fatigue and chronic fatigue syndrome: a systematic review. Quarterly Journal of Medicine 90, 223-233.

Klingers, C. \& Diepstraten, L. A. M. (1998). What is the meaning of the concept 'incapacity for work' [in Dutch]? Nederlandse Tijdschrift voor Geneeskunde 142, 671-684

Prins, J. B., Bleijenberg, G., Bazelmans, E., Elving, L. D., de Boo, T. M., Severens, J. L., van der Wilt, G. J., Spinhoven, P. \& van der Meer, J. W. (2001). Cognitive behaviour therapy for chronic fatigue syndrome: a multicentre randomised controlled trial. Lancet 357, 841-847.

Ross, S. D., Estok, R. P., Frame, D., Stone, L. R., Ludensky, V. \& Levine, C. B. (2004). Disability and chronic fatigue syndrome: a focus on function. Archives of Internal Medicine 164, 1098-1107.

Schaufeli, W. B., Leiter, M. P., Maslach, C. \& Jackson, S. E. (1996). The Maslach Burnout Inventory - General Survey. In Maslach Burnout Inventory Manual (ed. C. Maslach, S. E. Jackson and M. P. Leiter), pp. 19-26. Consulting Psychologists Press: Palo Alto, CA.

Schaufeli, W. B. \& Van Dierendonk, D. (2000). UBOS, Utrechtse Burnout Schaal: Dutch Translation of the Maslach Burnout Inventory (MBI) Manual. Swets Test Publishers: Lisse.
Schmaling, K. B., Fiedelak, J. I., Katon, W. J., Bader，J. O. \& Buchwald, D. S. (2003). Prospective study of the prognosis of unexplained chronic fatigue in a clinic-based cohort. Psychosomatic Medicine 65, 1047-1054.

Sharpe, M., Hawton, K., Seagroatt, V. \& Pasvol, G. (1992). Follow up of patients presenting with fatigue to an infectious diseases clinic. British Medical Journal 305, 147-152.

Skapinakis, P., Lewis, G. \& Mavreas, V. (2003). One-year outcome of unexplained fatigue syndromes in primary care: results from an international study. Psychological Medicine 33, 857-866.

Taylor, R. R., Jason, L. A. \& Torres, A. (2000). Fatigue rating scales an empirical comparison. Psychological Medicine 30, 849-856.

Van Amelsvoort, L. G., Kant, I. J., Beurskens, A. J., Schroer, C. A. \& Swaen, G. M. (2002). Fatigue as a predictor of work disability. Occupational and Environmental Medicine 59, 712-713.

Van der Werf, S. P., de Vree, B., Alberts, M., van der Meer, J. W. \& Bleijenberg, G. (2002). Natural course and predicting selfreported improvement in patients with chronic fatigue syndrome with a relatively short illness duration. Journal of Psychosomatic Research 53, 749-753.

Vercoulen, J. H., Swanink, C. M., Fennis, J. F., Galama, J. M., van der Meer, J. W. \& Bleijenberg, G. (1996). Prognosis in chronic fatigue syndrome: a prospective study on the natural course. Journal of Neurology, Neurosurgery and Psychiatry 60, 489-494.

Vercoulen, J. H. H. M., Alberts, M. \& Bleijenberg, G. (1999). The Checklist for Individual Strength (CIS) [in German]. Gedragstherapie 32, 131-136.

Ware Jr., J. E. \& Sherbourne, C. D. (1992). The MOS 36-item short-form health survey (SF-36). I. Conceptual framework and item selection. Medical Care 30, 473-483.

Wilson, A., Hickie, I., Lloyd, A., Hadzi-Pavlovic, D., Boughton, C., Dwyer, J. \& Wakefield, D. (1994). Longitudinal study of outcome of chronic fatigue syndrome. British Medical Journal 308, 756-759. 